\title{
Bone health status of postmenopausal Chinese women
}

\author{
Sue ST Lo *
}

\section{A B S T R A C T}

Objectives: To evaluate the prevalence of osteoporosis in treatment-naïve postmenopausal women, their treatment adherence, and the risk factors for osteoporosis.

Design: Cross-sectional study of bone density reports, a self-administered health checklist, and computerised consultation records.

Setting: Primary care sexual and reproductive health service in Hong Kong.

Participants: Postmenopausal Chinese women who had never received osteoporosis treatment or hormone replacement therapy.

Intervention: Each woman completed a checklist of risk factors for osteoporosis, menopause age, history of hormone replacement therapy, and osteoporosis treatment prior to undergoing bone mineral density measurement at the postero-anterior lumbar spine and left femur. The consultation records of those with osteoporosis were reviewed to determine their treatment adherence.

Main outcome measures: $\mathrm{T}$-score at the spine and hip, presence or absence of risk factors for osteoporosis, and treatment adherence.

This article was published on 16 Oct 2015 at www.hkmj.org.
Results: Between January 2008 and December 2011, 1507 densitometries were performed for eligible women; $51.6 \%$ of whom were diagnosed with osteopenia and $25.7 \%$ with osteoporosis. The mean age of women with normal bone mineral density, osteopenia, and osteoporosis was 57.0, 58.0, and 59.7 years, respectively. Approximately half of them had an inadequate dietary calcium intake, performed insufficient weight-bearing exercise, or had too little sun exposure. Logistic regression analysis revealed that age, body mass index of $<18.5 \mathrm{~kg} / \mathrm{m}^{2}$, parental history of osteoporosis or hip fracture, and duration of menopause were significant risk factors for osteoporosis. Among those with osteoporosis, $42.9 \%$ refused treatment, $30.7 \%$ complied with treatment, and $26.3 \%$ discontinued treatment or defaulted from follow-up. Those who refused treatment were significantly older.

Conclusions: Osteoporosis is prevalent in postmenopausal women. Only 50\% adopted primary prevention strategies. Almost 70\% refused treatment or stopped prematurely.

Hong Kong Med J 2015;21:536-41

DOI: $10.12809 / \mathrm{hkmj} 154527$

SST LO *, MD, FRCOG

The Family Planning Association of Hong Kong, 10/F, Southorn Centre, 130 Hennessy Road, Wanchai, Hong Kong

* Corresponding author: stlo@famplan.org.hk

New knowledge added by this study

- Osteoporosis affects one in four postmenopausal Chinese women in Hong Kong.

- Age, body mass index of $<18.5 \mathrm{~kg} / \mathrm{m}^{2}$, a positive parental history of osteoporosis or hip fracture, and duration of menopause are significant risk factors for osteoporosis.

- Only $31 \%$ of osteoporotic women complied with the treatment protocol.

Implications for clinical practice or policy

- This study showed that osteoporosis is prevalent in Hong Kong Chinese postmenopausal women. Doctors should encourage postmenopausal women to have an adequate calcium intake, perform sufficient weightbearing exercise, and have enough sun exposure. Those with risk factors should also undergo dual-energy X-ray absorptiometry to ascertain their bone status.

- Drug compliance is a problem in those with osteoporosis. Patient education should be provided to help them understand the importance of treatment compliance, the risk of fracture, and osteoporosis-associated morbidity and mortality.

\section{Introduction}

Osteoporosis is a major health problem in the elderly causing significant morbidity, mortality, and socioeconomic burden. Women are more vulnerable to osteoporosis than men because they have smaller and thinner bones. In addition, the sudden drop in ovarian oestrogen production around menopause causes women to lose bone rapidly. Accelerated bone loss begins about 2 to 3 years before the last menses and continues until 3 to 4 years after menopause. There is $2 \%$ bone loss annually around menopause, slowing to $1 \%$ to $1.5 \%$ annually thereafter. ${ }^{1,2}$ Bone mineral density (BMD) measurement by central dual-energy X-ray absorptiometry (DXA) is the gold 
standard for diagnosing osteoporosis. Bone mineral density is compared with the mean peak BMD for young adults of the same sex and ethnicity to calculate a T-score. The World Health Organization (WHO) defines osteoporosis as a BMD 2.5 standard deviations (SDs) below that of young-adult BMD and osteopenia as a BMD 1.0 to 2.5 SD below. ${ }^{3}$ A metaanalysis of prospective and case-control studies of BMD and fracture risk showed that the predictive value of BMD for fracture is at least as good as that of blood pressure for stroke. ${ }^{4}$ In a recent prospective study of postmenopausal Chinese women, the relative risk of fracture increased 2-fold (95\% confidence interval [CI], 1.6-2.5) for each decrease in SD of mean femoral-neck BMD. ${ }^{5}$

With urbanisation and adoption of a more sedentary lifestyle, the age-specific incidence of hip fracture in Hong Kong women increased by $300 \%$ between 1966 and 1985.6 The incidence levelled off between 1985 and 1995. 'Between 1995 and 2004, the incidence declined by $50 \%$ in those aged 50 to 59 years but remained stable for other age-groups. ${ }^{8}$ Although the age-specific incidence rates stabilise, the absolute number of hip fractures will continue to increase because of the ageing population. It has been estimated that in Hong Kong, 5293 women will have a hip fracture in the year $2015 . .^{9}$ The local prevalence of vertebral fracture in women has been estimated to be $30 \%{ }^{10}$ Osteoporotic fractures increase the morbidity and mortality of individuals and are a considerable burden on the health-care system. After the first fracture, the risk of subsequent fracture of an individual is 2.2 times higher than that of an individual without a prior fragility fracture $(95 \% \mathrm{CI}$, 1.9-2.6). ${ }^{11}$ Primary care physicians play a pivotal role in preventing this fracture cascade in postmenopausal women. They can help postmenopausal women improve bone health by encouraging them to adopt primary prevention strategies for osteoporosis and fall that may cause fracture; increasing their awareness of their personal risk for osteoporosis and taking action to minimise those risks; providing DXA assessment when indicated; and treating women who are diagnosed with osteoporosis. ${ }^{12}$ Pharmacological treatment can reduce the risk of osteoporotic fractures by $30 \%$ to $70 \%$. Treatment failure is partly due to poor drug compliance with treatment. In a systematic review of osteoporosis treatment with bisphosphonates, the yearly drug compliance rate was only $42.5 \%$ to $54.8 \%{ }^{13}$

The objectives of this study were to evaluate the prevalence of osteoporosis in treatment-naïve postmenopausal Chinese women, and determine the risk factors associated with osteoporosis and treatment compliance in those diagnosed with osteoporosis. These results will help physicians understand the bone health status of postmenopausal Chinese women.

\section{華裔女性停經後的骨骼健康狀況}

\section{羅善清}

目的：評估婦女停經後骨質疏鬆的比率和用藥遵從性，以及骨質疏鬆 症的高危因素。

設計：骨密度報告、自我填寫的健康檢查表和電腦病歷的横斷面研 究。

安排：在香港的基層性與生殖健康醫療保健服務。

參與者：從未接受骨質疏鬆症治療或荷爾蒙補充療法的停經後華裔婦 女。

介入治療：每位參與者均填寫一份健康檢查表, 列明其骨質疏鬆症的 高危因素、停經年齡、荷爾蒙補充療法紀錄, 以及所接受的骨質疏鬆 症治療。然後為她們在前後位腰椎和左股骨處量度骨質密度。患有骨 質疏鬆症的婦女, 會翻查其病歷以了解其用藥遵從性。

主要結果測量：脊柱和髖骨的 $\mathrm{T}$ 值、是否有骨質疏鬆症的高危因素, 以及用藥遵從性。

結果：2008年1月至2011年12月期間為符合條件的婦女進行了 1507 次 骨質密度檢查, 其中 $51.6 \%$ 被診斷為骨質稀薄, 另 $25.7 \%$ 患有骨質疏 鬆症。參與者的平均年齡如下：具正常骨密度的為57.0歲、骨質稀薄 的為 58.0 歲、有骨質疏鬆症的為59.7歲。約一半婦女從膳食攝入銔的 分量不足、進行負重練習不足或是接觸陽光的機會太少。邏輯迴歸分 析顯示年齡、身體質量指標在 $18.5 \mathrm{~kg} / \mathrm{m}^{2}$ 以下、父母有骨質疏鬆症或 髖部骨折的病史, 以及停經的持續時間均為骨質疏鬆症的顯著高危因 素。骨質疏鬆症患者中, $42.9 \%$ 拒絕治療, $30.7 \%$ 接受並遵從用藥指 示, 但有 $26.3 \%$ 提前停止治療或未有繼續覆診。拒絕治療的患者明顯 較年長。

結論：停經後婦女罹患骨質疏鬆症的情形非常普遍。只有 $50 \%$ 採取預 防的策略。幾乎有 $70 \%$ 拒絕或提前中止骨質疏鬆症的治療。

\section{Methods}

Postmenopausal women who attend the Women's Health Service in Hong Kong for menopause assessment are offered DXA testing of the spine and hip. Since a charge is made for the test, it is not universally accepted. The number of women who refused DXA was not captured. Prior to undergoing DXA, women completed a checklist of risk factors that included a history of parental osteoporosis or hip fracture, personal low trauma fracture, smoking habit, drinking habit, calcium intake, exercise habit, sun exposure, use of medication or presence of disease that causes bone loss, number of falls in the past 12 months, previous use of hormone replacement therapy, previous use of osteoporosis drugs, and current osteoporosis treatment. The BMD at the postero-anterior lumbar spine (L1-L4) and left femur (total hip, trochanter, Ward's triangle, and femoral neck) was measured using a Hologic QDR4000 machine (Hologic Inc, Bedford [MA], US) and performed by a single operator. The DXA report provided data on age, menopause age, body mass index (BMI), BMD, T-score, and Z-score. The 
checklist and DXA report were filed together by date.

This analysis was conducted by searching through paper records completed between January 2008 and December 2011. The research protocol was approved by the Ethics Panel of the Family Planning Association of Hong Kong. Non-Chinese women and those previously or currently prescribed hormone replacement therapy or osteoporosis treatment were excluded. The computerised consultation records of those with osteoporosis were searched to obtain treatment history. Our clinic only provides oral osteoporotic drugs (raloxifene, weekly alendronate, monthly ibandronate and strontium ranelate). The treatment plan, risks, and benefits of each drug, specific prescription required of each drug, and contra-indications are discussed with the patient before deciding the drug therapy. Patients are involved in decision making and must pay for treatment.

Descriptive statistics for basic demographic factors, risk factors for osteoporosis, T-score distribution, and treatment adherence were presented. Women were categorised into three subgroups according to their T-score and based on WHO recommendations ${ }^{3}$ : normal BMD (T-score $\geq-1.0$ at either the hip or spine), osteopenia ( $\mathrm{T}$ score between $<-1.0$ and -2.5 ), and osteoporosis (Tscore $<-2.5)$. The Chi squared test was used to test for a significant association between categorical risk factors and osteoporosis. Stepwise binomial logistic regression analysis using factors found to have a significant correlation with BMD of T-score of $<-2.5$ was performed to identify risk factors that best predict osteoporosis. Analysis of variance was used to analyse the difference between group means. Level of significance was set at alpha $=0.05$ for the two-tailed tests. Data analyses were performed using the Statistical Package for the Social Sciences (version 23.0; IBM, New York, US).

\section{Results}

Between January 2008 and December 2011, 1507 DXA scans were performed for eligible women. Their mean $( \pm \mathrm{SD})$ age was $58.2 \pm 6.4$ years and the mean age at menopause was $49.9 \pm 4.0$ years. The median duration of menopause (years from menopause to date of DXA) was 7 years (interquartile range, 3-11 years). The number of women with risk factors for osteoporosis in the whole group and subgroups are listed in Table 1 . Only $1 \%$ of participants were unable to recall whether or not there was a parental history of osteoporosis or hip fracture.

Osteoporosis was diagnosed in $25.7 \%$ of women and osteopenia in $51.6 \%$. The mean age of women with normal BMD, osteopenia, and osteoporosis was $57.0 \pm 5.6$ years, $58.0 \pm 6.4$ years, and 59.7 \pm 6.8 years, respectively $(\mathrm{P}<0.001)$. The mean age at menopause for each subgroup was the same: 50.0 years $(\mathrm{P}=0.441)$. Apart from age, $\mathrm{BMI}$ of $<18.5 \mathrm{~kg} / \mathrm{m}^{2}$ $(\mathrm{P}<0.001)$, duration of menopause $(\mathrm{P}<0.001)$, parental history of osteoporosis or hip fracture

TABLE I. Comparison of risk factors for osteoporosis among postmenopausal women with normal BMD, osteopenia, and osteoporosis (\% within group)

\begin{tabular}{|c|c|c|c|c|c|}
\hline \multirow[t]{2}{*}{ Risk factor for osteoporosis } & \multicolumn{4}{|c|}{ Mean \pm SD or No. (\%) } & \multirow[t]{2}{*}{$P$ value } \\
\hline & $\begin{array}{l}\text { Whole group } \\
(n=1507)\end{array}$ & Normal $(n=343)$ & $\begin{array}{l}\text { Osteopenia } \\
(n=777)\end{array}$ & $\begin{array}{l}\text { Osteoporosis } \\
(n=387)\end{array}$ & \\
\hline Age (years) & $58.2 \pm 6.4$ & $57.0 \pm 5.6$ & $58.0 \pm 6.4$ & $59.7 \pm 6.8$ & $<0.001$ \\
\hline Duration of menopause (years) & $8.3 \pm 6.8$ & $6.9 \pm 6.2$ & $8.1 \pm 6.5$ & $10.0 \pm 7.5$ & $<0.001$ \\
\hline Parent had osteoporosis or hip fracture & $290(19.2 \%)$ & $56(16.3 \%)$ & $138(17.8 \%)$ & $96(24.8 \%)$ & 0.024 \\
\hline Body mass index $<18.5 \mathrm{~kg} / \mathrm{m}^{2}$ & $75(5.0 \%)$ & $3(0.9 \%)$ & $34(4.4 \%)$ & $38(9.8 \%)$ & $<0.001$ \\
\hline $\begin{array}{l}\text { Personal history of significant medical disease, } \\
\text { eg thyrotoxicosis, rheumatoid arthritis, ankylosing } \\
\text { spondylitis, anorexia nervosa, hyperparathyroidism }\end{array}$ & $180(11.9 \%)$ & $33(9.6 \%)$ & $100(12.9 \%)$ & $47(12.1 \%)$ & 0.300 \\
\hline $\begin{array}{l}\text { Used drugs that caused bone loss, eg corticosteroid, } \\
\text { aromatase inhibitor, anticonvulsants, chemotherapy, } \\
\text { proton pump inhibitor, Depo-Provera* }\end{array}$ & $91(6.0 \%)$ & $19(5.5 \%)$ & $43(5.5 \%)$ & $29(7.5 \%)$ & 0.379 \\
\hline $\begin{array}{l}\text { Did not eat } 2-3 \text { servings of calcium-rich food or } \\
\text { calcium tablet daily }\end{array}$ & $755(50.1 \%)$ & $187(54.5 \%)$ & $368(47.4 \%)$ & $200(51.7 \%)$ & 0.067 \\
\hline Did not do 20 minutes of weight-bearing exercise daily & $706(46.8 \%)$ & $170(49.6 \%)$ & $339(43.6 \%)$ & $197(50.9 \%)$ & 0.033 \\
\hline No sun exposure in the past 1 week & $666(44.2 \%)$ & $167(48.7 \%)$ & $321(41.3 \%)$ & $178(46.0 \%)$ & 0.051 \\
\hline Smoke $>20$ cigarettes daily & $7(0.5 \%)$ & 0 & $7(0.9 \%)$ & 0 & 0.037 \\
\hline Drink alcohol daily & $3(0.2 \%)$ & 0 & $2(0.3 \%)$ & $1(0.3 \%)$ & 0.642 \\
\hline Had one or more falls in the past 12 months & $232(15.4 \%)$ & $52(15.2 \%)$ & $111(14.3 \%)$ & $69(17.8 \%)$ & 0.285 \\
\hline Previous low trauma fracture & $169(11.2 \%)$ & 32 (9.3\%) & $83(10.7 \%)$ & $54(14.0 \%)$ & 0.113 \\
\hline
\end{tabular}

Abbreviations: BMD = bone mineral density; SD = standard deviation

* Pharmacia \& Upjohn Co (Kalamazoo [MI], US) 
$(\mathrm{P}=0.024)$, and not doing 20 minutes of weightbearing exercise daily $(\mathrm{P}=0.033)$ were significant risk factors for osteoporosis. Although smoking is a significant risk factor for low bone mass, there were too few smokers in this group to make any meaningful comparison. The other risk factors did not show a significant association with osteoporosis (Table 1). The proportion of women who had risk factors and who had spine osteoporosis and hip osteoporosis is listed in Table 2. The results of the stepwise logistic regression analysis are shown in Table 3-only older age, low BMI, longer duration of menopause, and parental history remained significant.

Among the 387 women with osteoporosis, 166 (42.9\%) refused treatment because they feared of the side-effects of drugs, 119 (30.7\%) complied with the treatment provided, 45 (11.6\%) discontinued treatment due to side-effects or worry about sideeffects, and 57 (14.7\%) has defaulted from follow-up by March 2015. The common side-effects that concerned patients included hot flushes with raloxifene, gastric and musculoskeletal pain with bisphosphonates, and loose stools and diarrhoea with strontium ranelate. For major adverse events, patients were concerned about atypical fracture and osteonecrosis of the jaw with bisphosphonates and increased cardiac risk with strontium ranelate. Among the 119 women who complied with treatment, 20 were still on treatment in March 2015 and 99 were taking a drug holiday after 2 to 6 years' treatment that brought BMD to the osteopenic range. Those who refused treatment were significantly older with a mean age of $61.2 \pm 7.8$ years $(P<0.001)$.

\section{Discussion}

Osteoporosis is estimated to affect 200 million women worldwide, which is approximately one tenth of women aged 60 years, one fifth of those aged 70 years, two fifths of those aged 80 years, and two thirds of women aged 90 years. ${ }^{14}$ It has been estimated that approximately $30 \%$ of postmenopausal American women ${ }^{15}$ and $23 \%$ of postmenopausal Australian women have osteoporosis. ${ }^{16}$ The prevalence of osteoporosis in postmenopausal Indonesian women has been reported to be $20.2 \%$ in the lumbar vertebrae. ${ }^{17}$ In Germany, $23.3 \%$ of postmenopausal German women aged 50 to 64 years had osteoporosis. ${ }^{18}$ The prevalence of osteoporosis (25.7\%) in this study was similar to the prevalence rate

TABLE 2. Comparison of risk factors in different sites of osteoporosis (\% within group)

\begin{tabular}{|c|c|c|}
\hline \multirow[t]{2}{*}{ Risk factor } & \multicolumn{2}{|c|}{ Mean \pm SD or No. (\%) } \\
\hline & Spine osteoporosis $(n=383)$ & Hip osteoporosis $(n=33)$ \\
\hline Age (years) & $59.7 \pm 6.7$ & $65.9 \pm 9.2$ \\
\hline Duration of menopause (years) & $9.9 \pm 7.4$ & $16.7 \pm 10.7$ \\
\hline Parent had osteoporosis or hip fracture & $96(25.1 \%)$ & $6(18.2 \%)$ \\
\hline Body mass index $<18.5 \mathrm{~kg} / \mathrm{m}^{2}$ & $38(9.9 \%)$ & $9(27.3 \%)$ \\
\hline $\begin{array}{l}\text { Personal history of significant medical disease, eg thyrotoxicosis, rheumatoid } \\
\text { arthritis, ankylosing spondylitis, anorexia nervosa, hyperparathyroidism }\end{array}$ & $47(12.3 \%)$ & $3(9.0 \%)$ \\
\hline $\begin{array}{l}\text { Used drugs that caused bone loss, eg corticosteroid, aromatase inhibitor, } \\
\text { anticonvulsants, chemotherapy, proton pump inhibitor, Depo-Provera* }\end{array}$ & $29(7.6 \%)$ & 0 \\
\hline Did not eat 2-3 servings of calcium-rich food or calcium tablet daily & $197(51.4 \%)$ & $20(60.6 \%)$ \\
\hline Did not do 20 minutes of weight-bearing exercise daily & $194(50.7 \%)$ & $18(54.5 \%)$ \\
\hline No sun exposure in the past 1 week & $176(46.0 \%)$ & $17(51.5 \%)$ \\
\hline Drink alcohol daily & $1(0.3 \%)$ & 0 \\
\hline Had one or more falls in the past 12 months & $67(17.5 \%)$ & $10(30.3 \%)$ \\
\hline Previous low trauma fracture & $52(13.6 \%)$ & $5(15.2 \%)$ \\
\hline
\end{tabular}

Abbreviation: SD = standard deviation

* Pharmacia \& Upjohn Co (Kalamazoo [Ml], US)

TABLE 3. Stepwise logistic regression analysis evaluating risk factors for osteoporosis

\begin{tabular}{lcc}
\hline Risk factor & Odds ratio & 95\% Confidence interval \\
\hline Body mass index $<18.5 \mathrm{~kg} / \mathrm{m}^{2}$ & 3.19 & $2.00-5.09$ \\
Older age & 1.59 & $1.31-2.77$ \\
Longer duration of menopause & 2.47 & $1.45-3.01$ \\
Parent had osteoporosis or hip fracture & 1.57 & $1.19-2.07$ \\
Lack of exercise & 0.80 & $0.64-1.01$ \\
\hline
\end{tabular}


of $24.9 \%$ reported by another local epidemiological study. ${ }^{19}$ Because of the silent nature of osteoporosis, most patients who do not undergo DXA are unaware of the diagnosis. Realisation usually comes when a fragility fracture occurs.

Screening DXA is recommended for women aged 65 years and over as well as for at-risk younger women. ${ }^{20,21}$ In our subjects, age, low BMI, positive parental history of osteoporosis or hip fracture, and duration of menopause were significant risk factors. The Osteoporosis Self-assessment Tool for Asians is a simple validated tool that can determine the need for DXA, based on age and body weight. ${ }^{22}$ Osteoporosis has been shown by many studies to have a strong genetic influence. ${ }^{23-25} \mathrm{~A}$ parental history of fracture, particularly of the hip, confers an increased risk of fracture that is independent of BMD. ${ }^{26}$ Most of our patients could remember their menopause age and provide a parental history of osteoporosis or hip fracture for assessment.

Apart from delineating the magnitude of osteoporosis among postmenopausal women, this study also showed that almost half of them did not have an adequate calcium intake, and did not perform sufficient weight-bearing exercise or have enough sun exposure. The National Osteoporosis Foundation (NOF) recommends $1200 \mathrm{mg}$ calcium and 800 to 1000 IU vitamin D daily for women aged 50 and beyond. ${ }^{21}$ Nearly all Asian countries fall far below this recommendation. The median dietary calcium intake for the adult Asian population is approximately $450 \mathrm{mg} /$ day. $^{9}$ The recent calcium calculator launched by the International Osteoporosis Foundation (IOF) is a useful tool to help women assess their daily calcium intake (http:// www.iofbonehealth.org/calcium-calculator). Studies carried out across different countries in South and South-East Asia have shown, with few exceptions, widespread prevalence of vitamin D deficiency and insufficiency in both sexes and all age-groups of the population. ${ }^{27}$ The IOF therefore recommends $800 \mathrm{IU} /$ day vitamin D for everyone, even for those with regular effective sun exposure. ${ }^{28}$ The NOF also recommends regular weight-bearing and musclestrengthening exercise to improve agility, strength, posture, and balance. This may reduce the risk of falls and fractures. ${ }^{9}$ There is clear evidence that tai chi is effective for fall prevention and improving psychological health and is associated with general health benefits for older people. ${ }^{29}$ Meta-analysis of the effect of tai chi on osteoporosis or BMD is, however, inconclusive as a result of many different tai chi exercises being studied, and variable design and different quality-rating instruments used in the systematic reviews of tai chi literature. ${ }^{30}$ We were unable to show a significant association of diet, exercise, and sun exposure with osteoporosis in this cohort, probably due to limitations in capturing accurate information as discussed below. The important message to emphasise is that, in this group of self-selected clinic attendees who are in general believed to be more health conscious, the proportion of women adopting such healthy lifestyle strategies was not high. The situation in the general population might be worse. Since these are important lifestyle strategies for osteoporosis prevention, clinicians should encourage all postmenopausal women to adopt them.

It is of concern that in this study almost $43 \%$ of women with osteoporosis refused treatment. Among those who agreed to start treatment, only half adhered to treatment. Some women decided to stop treatment prematurely because they were distressed by reports of major adverse events such as atypical fracture and osteonecrosis of the jaw. Some women read news articles that stated treatment should not exceed 2, 3, or 5 years, then refused to continue treatment beyond this time frame. Although bisphosphonates are long-acting drugs, extended dosing does not compensate for poor drug compliance. A recent study showed that $64.0 \%$ of patients discontinued weekly alendronate, $66.4 \%$ discontinued weekly risedronate, and $68.2 \%$ discontinued monthly ibandronate. ${ }^{31}$ Hence dosing regimens are unlikely to be solely responsible for poor compliance. Other factors that reduced drug compliance included: cost of medication, low motivation to take drug as patients were asymptomatic, patients did not believe they were at significant risk of fracture, some patients had difficulty complying with the prescribed regimen for bisphosphonates and strontium ranelate in the context of their daily routine, the patient was already on a number of medications for other illnesses and refused more. Further research is needed to understand patient decision-making models for osteoporosis treatment and how health education from various sources (health-care providers, family, friends, and media) can modify their attitude towards osteoporosis treatment.

The main limitations of this study are: first, selection bias because some women refused to have DXA. The study women were therefore selfselected, hence the prevalence reported might not be representative of the population. Second, the information in the checklist was provided by patient recall and their responses were not verified. Similarly, the menopause age was provided by the patient and could not be verified. Third, the monitoring period was insufficient to provide fracture data that would allow comparison of outcome in patients who adhered to treatment and those who did not. Fourth, drug compliance (whether the drug was taken correctly), drug omission, stockpiling or transfer of medicines between friends and relatives were not assessed in detail. 


\section{Conclusions}

Osteoporosis is prevalent in the local population, affecting one in four postmenopausal women. Those with risk factors such as low BMI, older age, longer duration since menopause, and parental history of osteoporosis or hip fracture, should undergo DXA. In addition to prompt diagnosis and treatment of osteoporosis, physicians should monitor patient drug compliance at each follow-up. At the same time, calcium intake, sun exposure, and exercise pattern should also be evaluated to help optimise their bone health.

\section{References}

1. Recker RR, Lappe J, Davies K, Heaney R. Characterization of perimenopausal bone loss: a prospective study. J Bone Miner Res 2000;15:1965-73.

2. Pouillès JM, Trémollières $F$, Ribot $C$. Vertebral bone loss in perimenopause. Results of a 7-year longitudinal study [in French]. Presse Med 1996;25:277-80.

3. Assessment of fracture risk and its application to screening for postmenopausal osteoporosis. WHO Technical Report Series 843. Geneva: World Health Organization; 1994.

4. Marshall D, Johnell O, Wedel H. Meta-analysis of how well measures of bone mineral density predict occurrence of osteoporotic fractures. BMJ 1996;312:1254-9.

5. Kung AW, Lee KK, Ho AY, Tang G, Luk KD. Ten-year risk of osteoporotic fractures in postmenopausal Chinese women according to clinical risk factors and BMD T-scores: a prospective study. J Bone Miner Res 2007;22:1080-7.

6. Lau EM, Cooper C. The epidemiology of osteoporosis. The oriental perspective in a world context. Clin Orthop Relat Res 1996;323:65-74.

7. Lau EM, Cooper C, Fung H, Lam D, Tsang KK. Hip fracture in Hong Kong over the last decade-a comparison with the UK. J Public Health Med 1999;21:249-50.

8. Kung AW, Yates S, Wong V. Changing epidemiology of osteoporotic hip fracture rates in Hong Kong. Arch Osteoporos 2007;2:53-8.

9. The Asian Audit. Epidemiology, costs and burden of osteoporosis in Asia 2009. International Osteoporosis Foundation; 2009. Available from: http://www. iofbonehealth.org/sites/default/files/PDFs/Audit\%20Asia/ Asian_regional_audit_2009.pdf. Accessed 26 Jan 2015.

10. Lau EM, Chan HH, Woo J, et al. Normal ranges for vertebral height ratios and prevalence of vertebral fracture in Hong Kong Chinese: a comparison with American Caucasians. J Bone Miner Res 1996;11:1364-8.

11. Center JR, Bliuc D, Nguyen TV, Eisman JA. Risk of subsequent fracture after low-trauma fracture in men and women. JAMA 2007;297:387-94.

12. International Osteoporosis Foundation. The Breaking Spine. 2010. Available from: http://share.iofbonehealth. org/WOD/2010/thematic_report/2010_the_breaking_ spine_en.pdf. Accessed 22 May 2015.

13. Cramer JA, Gold DT, Silverman SL, Lewiecki EM. A systematic review of persistence and compliance with bisphosphonates for osteoporosis. Osteoporos Int 2007;18:1023-31.

14. Kanis JA. Assessment of osteoporosis at the primary health care level. Report of a WHO Scientific Group. Technical Report. World Health Organization Collaborating Centre for Metabolic Bone Diseases, University of Sheffield, UK; 2007. Available from: http://www.iofbonehealth.org/sites/ default/files/WHO_Technical_Report-2007.pdf. Accessed 22 May 2015.

15. Melton LJ 3rd, Chrischilles EA, Cooper C, Lane AW, Riggs BL. Perspective: How many women have osteoporosis? J Bone Miner Res 1992;7:1005-10.

16. Estimating the prevalence of osteoporosis in Australia. Cat. no. PHE 178. Canberra: Australian Institute of Health and Welfare (AIHW); 2014. Available from: http://www.aihw. gov.au/WorkArea/DownloadAsset.aspx?id=60129548481. Accessed 22 May 2015.

17. Meiyanti. Epidemiology of osteoporosis in postmenopausal women aged 47 to 60 years. Univ Med 2010;29:169-76. Available from: http://www.univmed.org/wp-content/ uploads/2011/02/Meiyanti.pdf. Accessed 22 May 2015.

18. Häussler B, Gothe H, Göl D, Glaeske G, Pientka L, Felsenberg D. Epidemiology, treatment and costs of osteoporosis in Germany-the BoneEVA Study. Osteoporos Int 2006;18:77-84.

19. Lau EM, Chung HL, Ha PC, Tam H, Lam D. Bone mineral density, anthropometric indices, and the prevalence of osteoporosis in Northern (Beijing) Chinese and Southern (Hong Kong) Chinese women-the largest comparative study to date. J Clin Densitom 2015 Jan 13. Epub ahead of print.

20. 2013 Official Positions of the International Society for Clinical Densitometry. Available from: http://www.iscd. org/documents/2014/02/2013-iscd-official-positionbrochure.pdf. Accessed 26 Jan 2015.

21. National Osteoporosis Foundation. The clinician's guide to prevention and treatment of osteoporosis 2014. Available from: http://nof.org/files/nof/public/content/file/2791/ upload/919.pdf. Accessed 26 Jan 2015.

22. Koh LK, Sedrine WB, Torralba TP, et al. A simple tool to identify Asian women at increased risk of osteoporosis. Osteoporos Int 2001;12:699-705.

23. Pocock NA, Eisman JA, Hopper JL, Yeates MG, Sambrook PN, Eberl S. Genetic determinants of bone mass in adults. A twin study. J Clin Invest 1987;80:706-10.

24. Seeman E, Hopper JL, Bach LA, et al. Reduced bone mass in daughters of women with osteoporosis. N Engl J Med 1989;320:554-8.

25. Thijssen JH. Gene polymorphisms involved in the regulation of bone quality. Gynecol Endocrinol 2006;22:131-9.

26. Kanis JA, Johansson H, Oden A, et al. A family history of fracture and fracture risk: a meta-analysis. Bone 2004;35:1029-37.

27. Mithal A, Wahl DA, Bonjour JP, et al. Global vitamin D status and determinants of hypovitaminosis D. Osteoporos Int 2009;20:1807-20.

28. Dawson-Hughes B, Mithal A, Bonjour JP, et al. IOF position statement: vitamin D recommendations for older adults. Osteoporos Int 2010;21:1151-4.

29. Lee MS, Ernst E. Systematic reviews of t'ai chi: an overview. Br J Sports Med 2012;10:713-8.

30. Alperson SY, Berger VW. Opposing systematic reviews: the effects of two quality rating instruments on evidence regarding t'ai chi and bone mineral density in postmenopausal women. J Altern Complement Med 2011;17:389-95.

31. Fan T, Zhang Q, Sen SS. Persistence with weekly and monthly bisphosphonates among postmenopausal women: analysis of a US pharmacy claims administrative database. Clinicoecon Outcomes Res 2013;5:589-95. 